\title{
Improvement of bearing performance on exterior steel beam- reinforced concrete column joints with steel columns
}

\author{
Shinya Nakaue ${ }^{a *}$, Yasushi Nishimura ${ }^{b}$ \\ ${ }^{a}$ Graduate School, Osaka Institute of Technology, Osaka 535-8585, Japan \\ brofessor, Department of Architecture, Faculty of Engineering, Osaka Institute of Technology, Osaka 535- \\ 8585, Japan \\ *corresponding author, e-mail address:m1m17207@oit.ac.jp
}

\begin{abstract}
To improve the bearing failure behavior of the exterior steel beam-reinforced concrete column joints composed of reinforced concrete columns, joint details using steel column was proposed. Steel column was attached to the lower flanges at right angles to the steel flange. The objective of this study is to clarify the effectiveness of proposed joint details experimentally and theoretically.

To clarify the influence of steel column on the bearing failure of the joint, seven T-shaped subassemblages were tested under reversed cyclic loading. All specimens had the same cross sections of the steel beam. The experimental variables were the embedded length of the steel column, whether there is the end plate at the tip of the embedded steel column, and, the arrangement of transverse reinforcement ratio surrounding the steel column.

The following remarks can be drawn from the test results.

1) In the case of the specimen with a short embedded length of the steel column, the punching shear failure on the upper surface of the steel beam flange was remarkable when the maximum strength was reached. However, in the specimen with long embedded length of steel column, the punching shear failure was not significant observed.

2) The maximum strength increased with the embedded length of the steel column. Further, the maximum strength of the specimen with the embedded length of three times of the steel column depths is subjected to bending yield strength of the steel column.

3) It was shown that the transverse reinforcement surrounding the $S$ column and the end plate were key components for improving the bearing resistance of the joint.
\end{abstract}

Keywords: S beam; RC Columns; Beam-Column Joints; Bearing Failure Behavior; Punching ShearFailure.

\section{Introduction}

In Japan, many kinds of details on steel(S)reinforced concrete (RC) joints have been proposed. One clear trend in composite construction has been the increased use of frames with $\mathrm{S}$ beams and $\mathrm{RC}$ columns. It is very important to clarify the behavior of the joints because seismic performance of the frame is considerably influenced by that of the joints. So far studies on the $\mathrm{S}$ beam-RC column joints were carried out to make sure of seismic performance at the various laboratories.

For the $\mathrm{S}$ beam-RC column joints, shear failure and bearing failure are the key failure modes. The shear failure mode indicates stable hysteresis loop without the strength degradation. On the other hand, the bearing failure mode indicates large pinching and strength degradation after the attainment of the maximum load. Accordingly, the bearing failure in the joints should not be caused in RCS system. Particularly, roof level exterior joints in the frame is remarkable the punching shear failure of the concrete on the upper surface of the $S$ flange.

To improve the bearing failure behavior of the T-shaped joint details using $\mathrm{S}$ column was proposed. S column was attached to the lower flanges at right angles to the $S$ flange. 
The objective of this study is to clarify the effectiveness of proposed joint details experimentally and theoretically, and is to propose bearing design formulae taken account of the effect of $\mathrm{S}$ column based on the stress transferring mechanism and resistance mechanism proposed by authors.

\section{Evaluation of ultimate strength based on Stress transferring mechanisms and resistance mechanism}

The $\mathrm{S}$ beam-RC column joints is assumed to be composed of the inner panel with the $S$ flange width and the outer panel outside the $\mathrm{S}$ flange. The ultimate strength of the joint is assumed to be estimated by superposing that of the inner panel and the outer panel. In the case of the Tshaped exterior joints, the ultimate strength of the inner panel is determined by the punching shear failure of the concrete occured by the bearing stress acting on the upper surface of the $\mathrm{S}$ flange. Fig. 1 shows the resistance mechanism and the stress transfer mechanism of the $\mathrm{T}$ shaped joint. As shown in Fig. 1 (a), the punching shear stress is evaluated by using the horizontal projection area $A p$ when the bearing stress is transferred in the angle $\gamma$ direction. The bearing stress with punching shear failure is assumed to act on the region of $0.3 D_{c s} b\left(D_{c}=\right.$ column depths; ${ }_{s} b=$ beam width). On the other hand, the resistance mechanism and the stress transfer mechanism of the $\mathrm{S}$ column attached to the $S$ beam are shown in Figs. 1 ( $b$ and $c$ ). When under reversed cyclic loading load is applied to the $\mathrm{S}$ beam, shear force $Q$ and bending moment $M$ are applied to the $\mathrm{S}$ column joint section. $Q$ and $M$ are resistanced by the bearing stress $\sigma_{p}$ acting on the inner surface of the $S$ column flange. The outward thrust force $R$ at the inner surface of the compression struts are resisted by transverse reinforcing bar arranged around the $S$ column. As a result of this stress transfer, the truss mechanisms are developed in the region outside the $\mathrm{S}$ column.

The ultimate strength of the outer panel is evaluated by the arch mechanism as shown in Fig. 2. The vertical component of the compressive forces acting on the compression struts are resisted by the tensile strength of the reinforcing bar, and horizontal component forces are controlled by the torsional strength transferred from the inner panel to the outer panel.

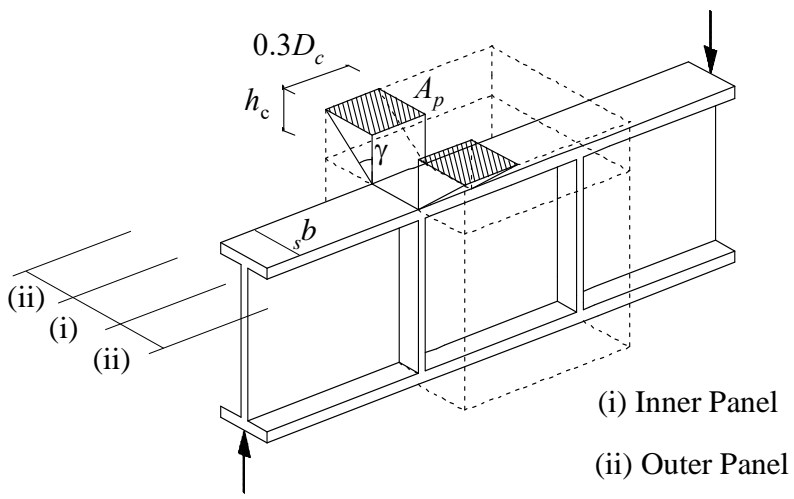

(a) punching shear failure (Nishimura et.al., 2014)

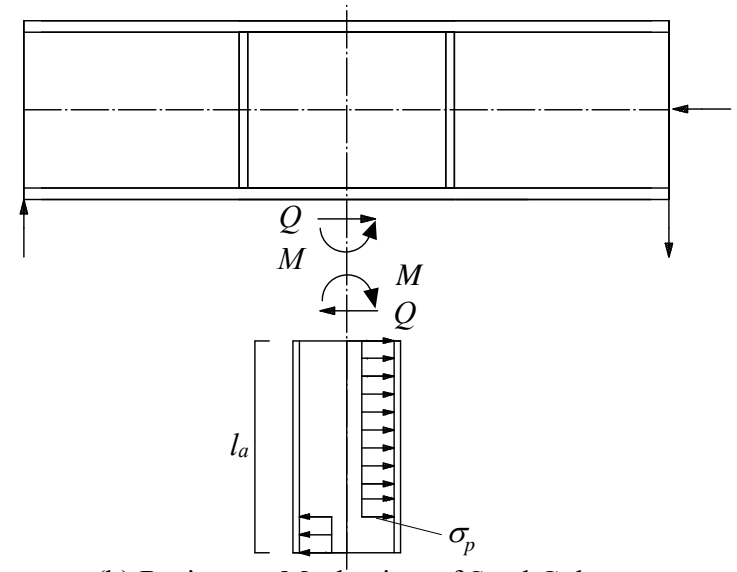

(b) Resistance Mechanism of Steel Column (Nishimura et.al., 2014)
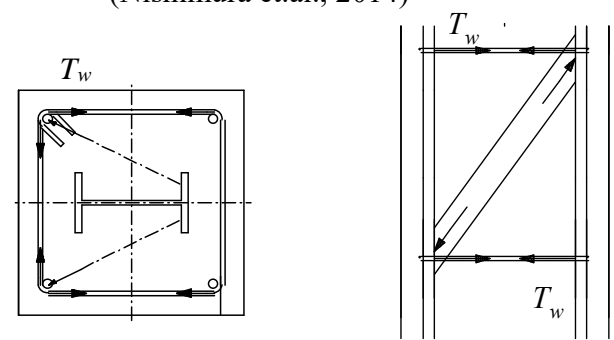

(c) Stress Trsnsferring Mechanism and Resistance Mechanism to RC Column (Nishimura et.al., 2014)

Fig. 1. Stress Trsnsferring Mechanism and Resistance Mechanism of Inner Panel

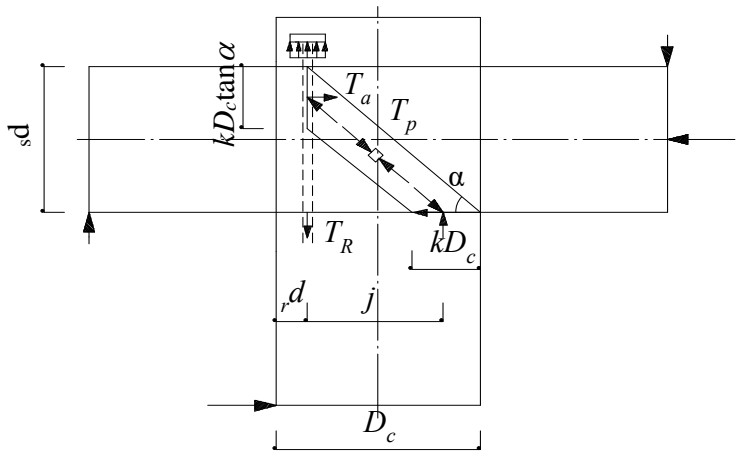

Fig. 2. Resistance Mechanism of Outer Panel (Nishimura et.al., 2014) 


\section{Experiment}

To clarify the effectiveness of the proposed joint details, seven T-shaped beam-column subassemblies under reversed cyclic loading were tested. The overall dimensions of the specimen, the cross sections and reinforcement details are shown in Fig. 3. All specimens were exterior T-shaped beam-column joints with 300 $\mathrm{mm}$ square columns and $\mathrm{S}$ beam with the width of $100 \mathrm{~mm}$ and the depth of $250 \mathrm{~mm}$, and specimen featured a steel beam passing continuously through the column. In addition, all specimens were designed enforce joint shear failure of the inner panel does not occur.
The joints details and the experimental variables are shown in Fig. 4 and 5. The cross sictoin of $\mathrm{S}$ column was the width of $80 \mathrm{~mm}$ and the depth of $150 \mathrm{~mm}$. The experimental variables on Experiment (I) as shown in Fig. 4 were the embedded length of the $S$ column. The transverse reinforcement ratio of $\mathrm{RC}$ column arranged around the $\mathrm{S}$ column was $0.35 \%$. Specimen TB-0D dose not has the embedded S column. Specimens TB-1D and TB-2D, and TB3D have the embedded steel column length of $150 \mathrm{~mm}$ and $300 \mathrm{~mm}$, and $450 \mathrm{~mm}$.

On the other hand, as shown in Fig. 5. the experimental variables on Experiment (II) were the end plate at the tip of the embedded S column and the arrangement of transverse reinforcement

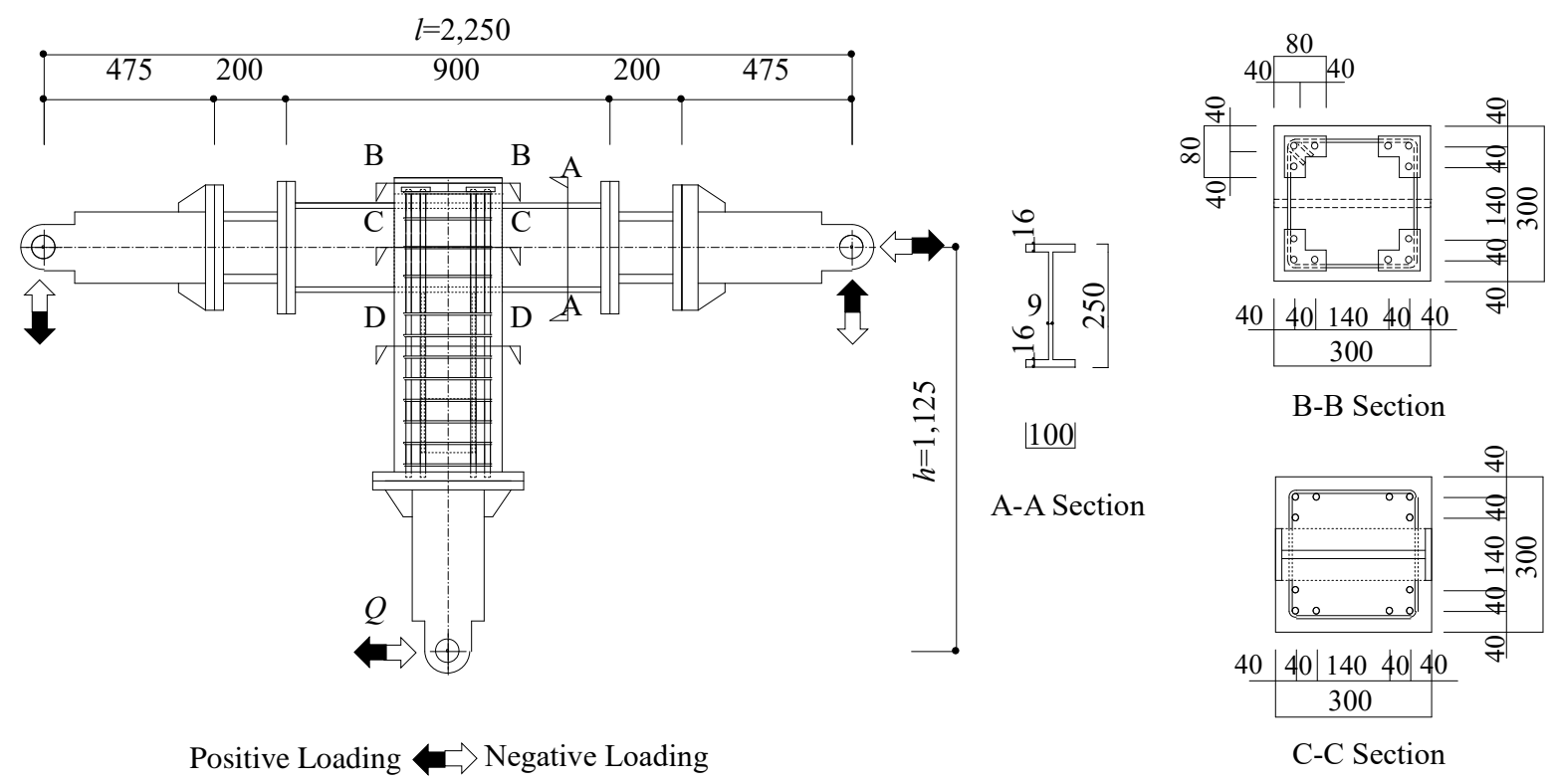

Fig. 3. Details of Specimens

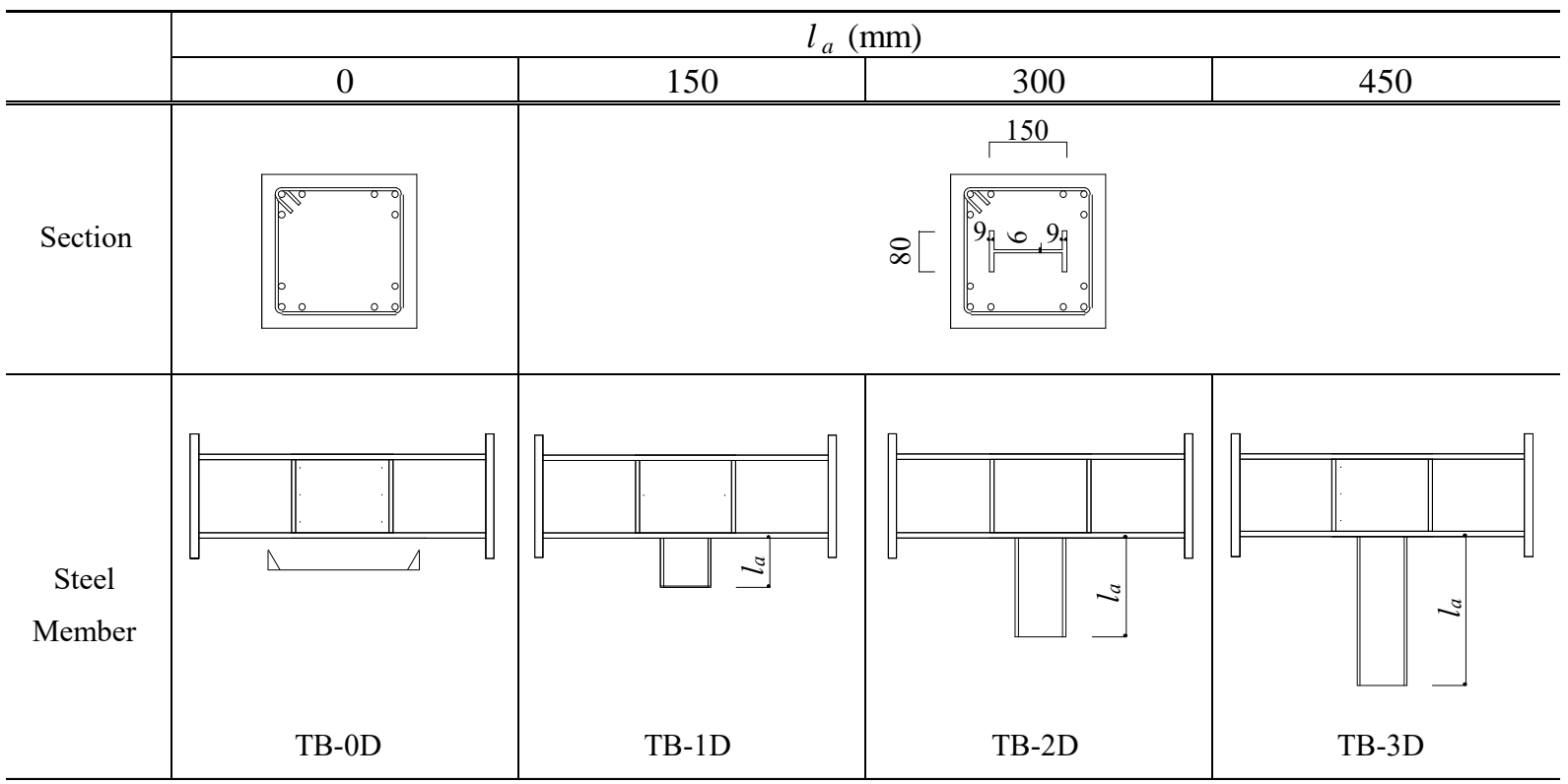

Fig. 4. Experimental Variables (Experiment (I)) 


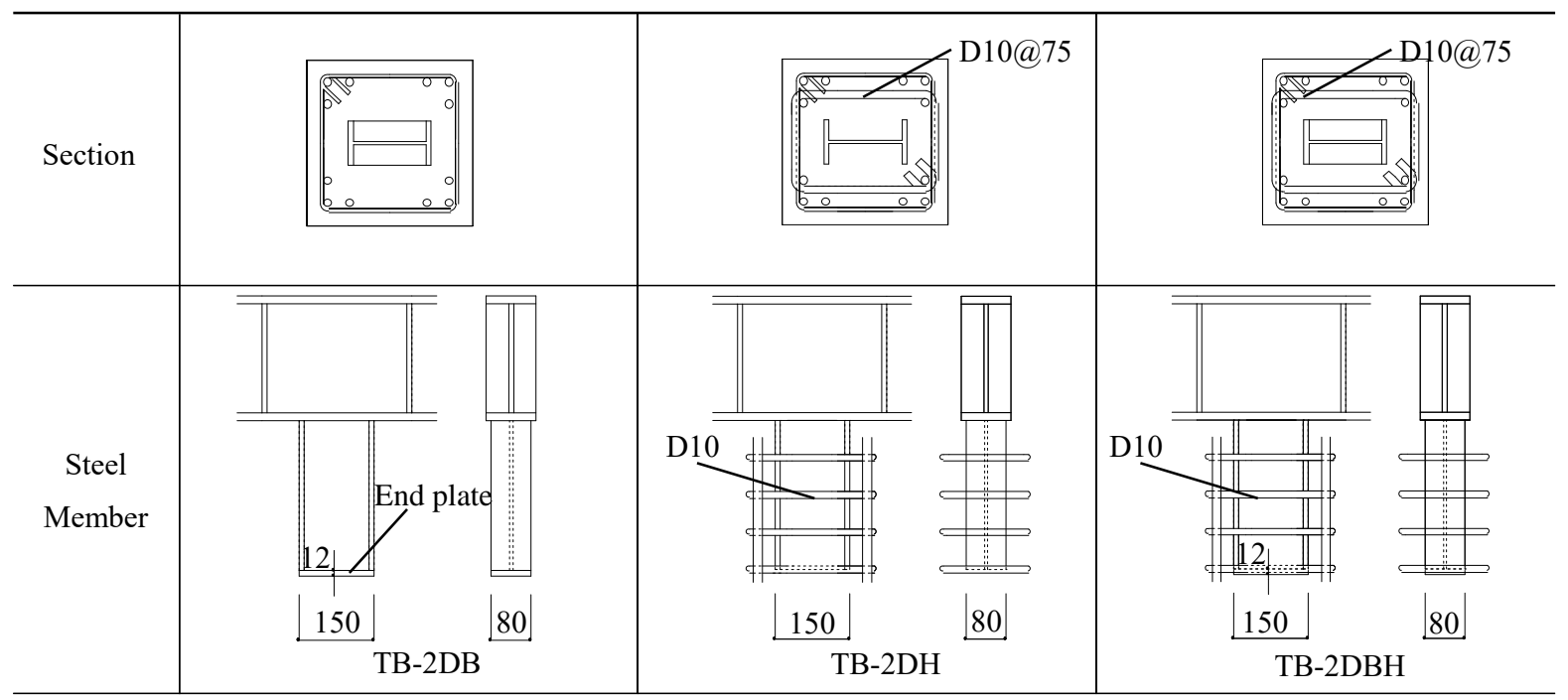

Fig. 5. Experimental Variables (Experiment (II))

Table 1. Mechanical Poperties of Materials

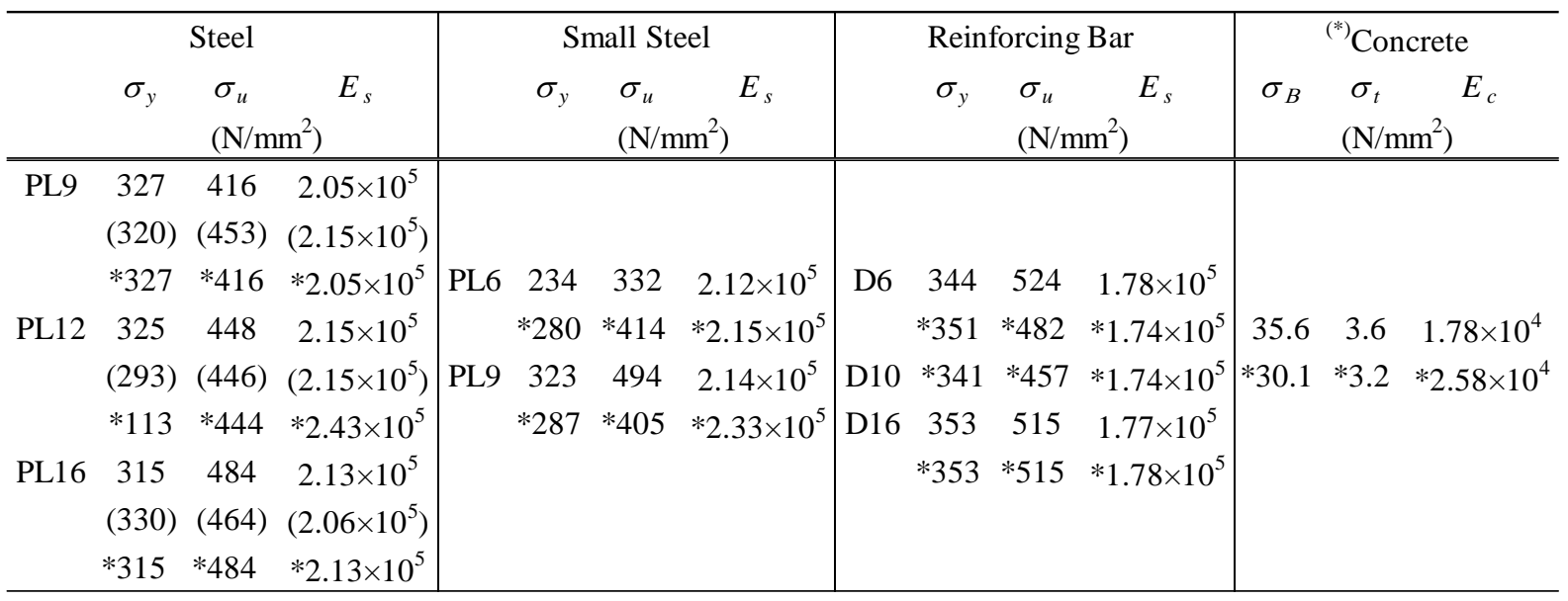

$\sigma_{y}=$ Yield Stress; $\sigma_{u}=$ Maximum Stress; $E_{s}=$ Young's Modulus; $\sigma_{B}=$ Compressive Stress; $\sigma_{t}=$ Splittimg Stress;

$E_{c}=$ Young's Modulus; ()$=$ Values used for Specimen TB-1D; * = Values used for Experiment (II); $(*)=$ Cylinder Strenght.

ratio surrounding the $\mathrm{S}$ column. The embedded length of the $S$ column is $300 \mathrm{~mm}$. Specimen TB2DB has the end plate at the tip of the the embedded S column. Specimen TB-2DH has the transverse reinforcement ratio of $\mathrm{RC}$ column arranged around the $\mathrm{S}$ column was $0.98 \%$. Specimen TB-2DBH has both reinforcing methods of Specimen TB-2DB and TB-2DH.

The mechanical properties of the materials are listed in Table 1.

The intended displacement regime used in this investigation is shown in Fig. 6. This displacement history consisted of lateral displacement cycles ranging from 1.0 to $5.0 \%$ drift. Since a small axial force acts on the RC column connected to the roof level T-shaped joint, no axial force is applied to the RC column.

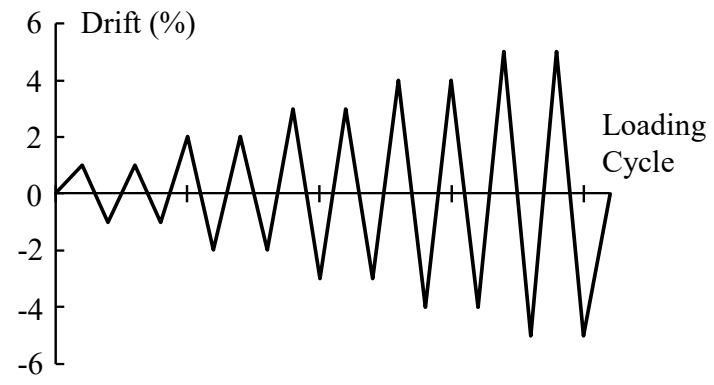

Fig. 6. Lateral Displacement History

\section{Test results \\ 4.1. Destructive and Hysteresis property \\ (Experiment (I))}

Concrete crushing in the maximum load and load-displacement relationships are shown in Fig. 6 . The vertical axis represents the applied load at the column. The horizontal axis gives the 


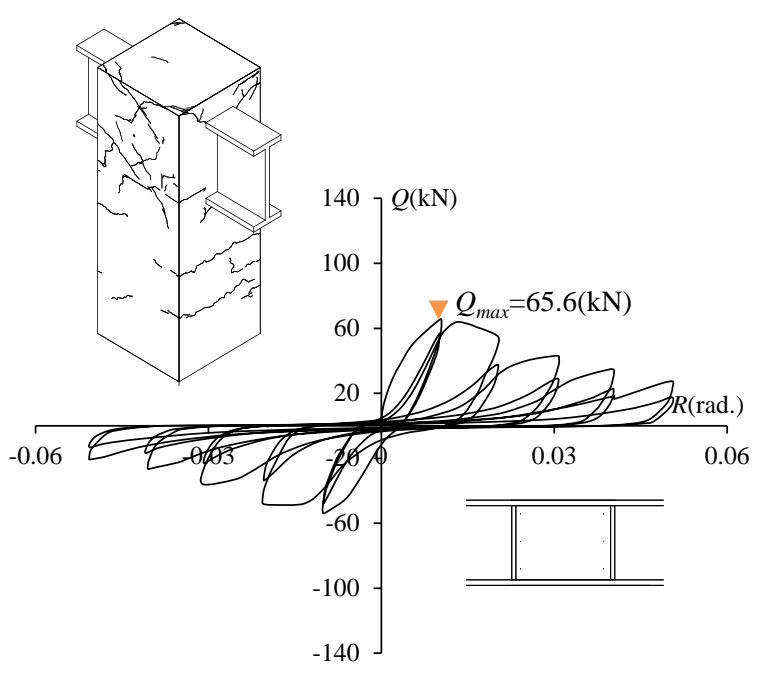

(a) Specimen TB-0D

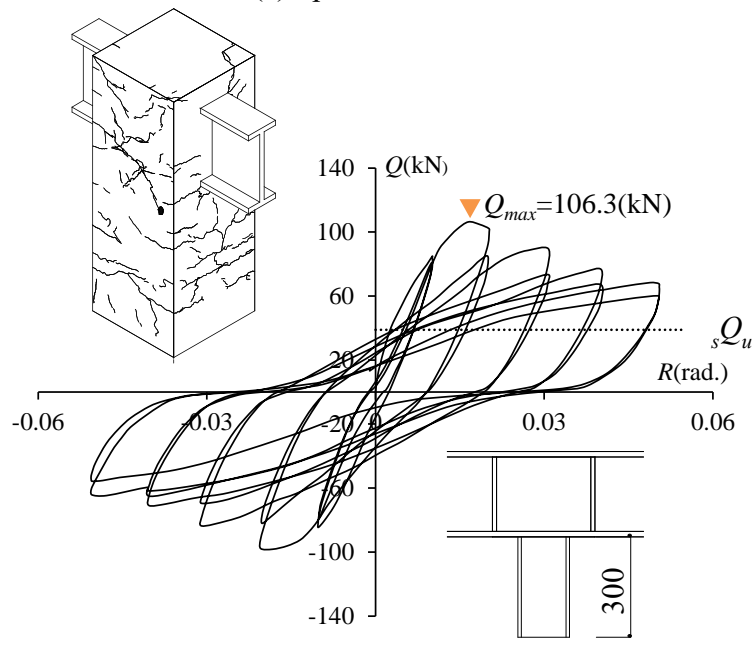

(c) Specimen TB-2D

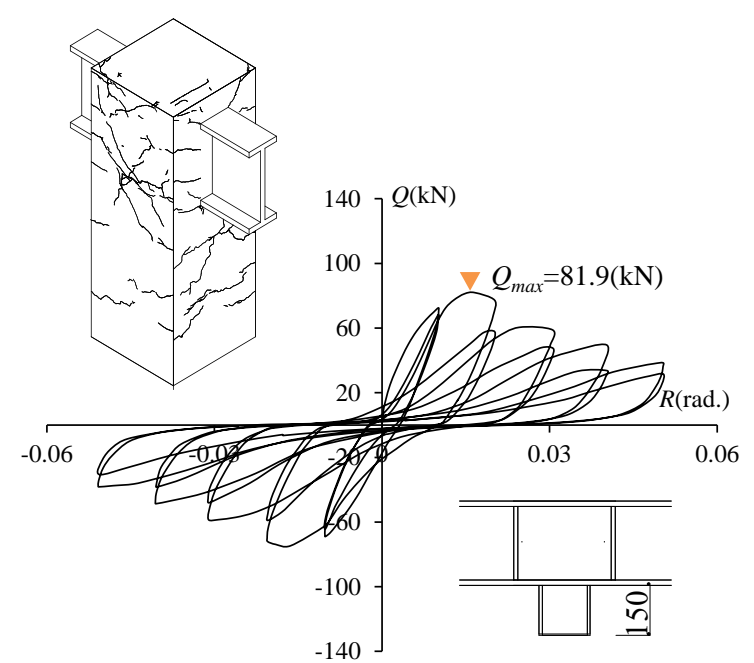

(b) Specimen TB-1D

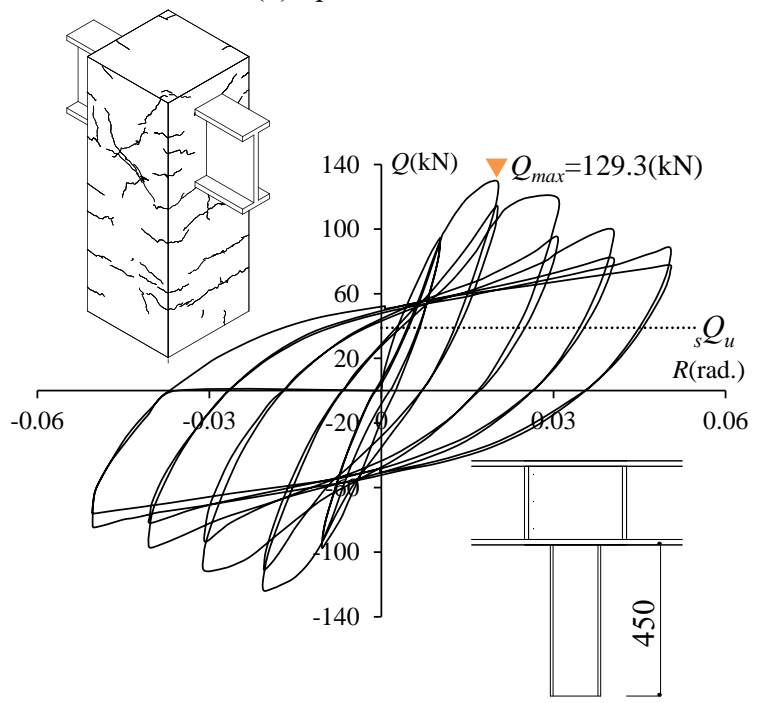

(d) Specimen TB-3D

Fig. 7. Hysteresis Loops and Concrete Crushing of Maximum Load (Experiment (I))

deflection of the column relative to the beam at the end of the column. ${ }_{s} Q_{u}$ shown in Fig. 7 (b)(d) is the bending strength to plastic bending moment of $\mathrm{S}$ column, and $Q_{\max }$ is the maximum load. In the case of specimens with the embedded S column length of $0-300 \mathrm{~mm}$, the punching shear failure of the concrete topping above the steel beem were observed in the maximum load. However, Specimen TB-03D with the embedded S column length of $400 \mathrm{~mm}$ was not observed the punching shear failure. In addition, it was shown that shear crack caused in concrete of the joint increased with the embedded S column length.

Specimen TB-1D had the maximum load more than TB-0D. However, the hysteresis loop of both specimens shown the reversed S-shape. The sliding properties on the hysteresis loop of Specimen TB-2D was greatly improved by the effect of embedded $S$ column compared to Specimen TB-OD and TB-1D. On the other hand, the sliding properties for Specimen TB-3D was not observed, and a stable hysteresis energy absorbing ability.

Fig. 8 shows the envelope curves for hysteresis loops. The effect of the embedded length of the S column on the initial stiffness and deterioration of the strength after the maximum load were not observed. However, the maximum load and the drift angle in the maximum load increased with the embedded length of the $\mathrm{S}$ column. From this test results, the maximum strength of the specimen with the embedded length of three times of the S column depths is subjected to bending yield strength of the $S$ column and reduce the punching shear failure at the inner panel. 
Table 2. Comparison of Calculated Values and Experimental Values (Experiment (I))

\begin{tabular}{c|c|c|c|c|c|c|c}
\hline \multirow{2}{*}{ Specimen } & \multirow{2}{*}{$\begin{array}{c}M_{\text {exp. }} \\
(\mathrm{kN} \cdot \mathrm{m})\end{array}$} & $\begin{array}{c}{ } M \\
(\mathrm{kN} \cdot \mathrm{m})\end{array}$ & $\begin{array}{c}{ }_{r} M_{h} \\
(\mathrm{kN} \cdot \mathrm{m})\end{array}$ & $\begin{array}{r}{ }_{r} M_{b} \\
(\mathrm{kN} \cdot \mathrm{m})\end{array}$ & $\begin{array}{c}{ }_{o} M \\
(\mathrm{kN} \cdot \mathrm{m})\end{array}$ & $\begin{array}{c}{ }_{p} M \\
(\mathrm{kN} \cdot \mathrm{m})\end{array}$ & $M_{\text {exp. }} /{ }_{p} M$ \\
\hline \hline TB-0D & 73.8 & 22.2 & 0 & 0 & 65.9 & 88.0 & 0.84 \\
\hline TB-1D & 92.1 & 22.5 & 3.3 & 48.2 & 67.7 & 93.5 & 0.99 \\
\hline TB-2D & 119.6 & 22.5 & 16.5 & 192.6 & 67.7 & 106.8 & 1.12 \\
\hline TB-3D & 145.4 & 23.0 & 34.7 & 433.4 & 70.3 & 127.9 & 1.14 \\
\hline
\end{tabular}

${ }_{r} M_{h}=$ Strength of Transverse Reinforcement; ${ }_{r} M_{b}=$ Bearing Strength; ${ }_{o} M=$ Strength of Outer Panel;

${ }_{p} M=$ Calculated Values.

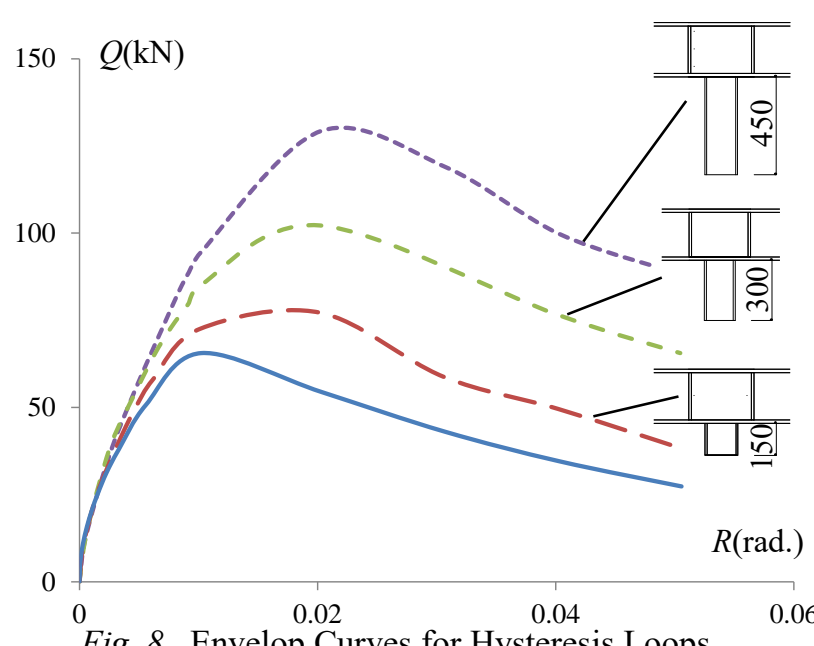

Fig. 8. Envelop Curves for Hysteresis Loops

(Experiment (I))

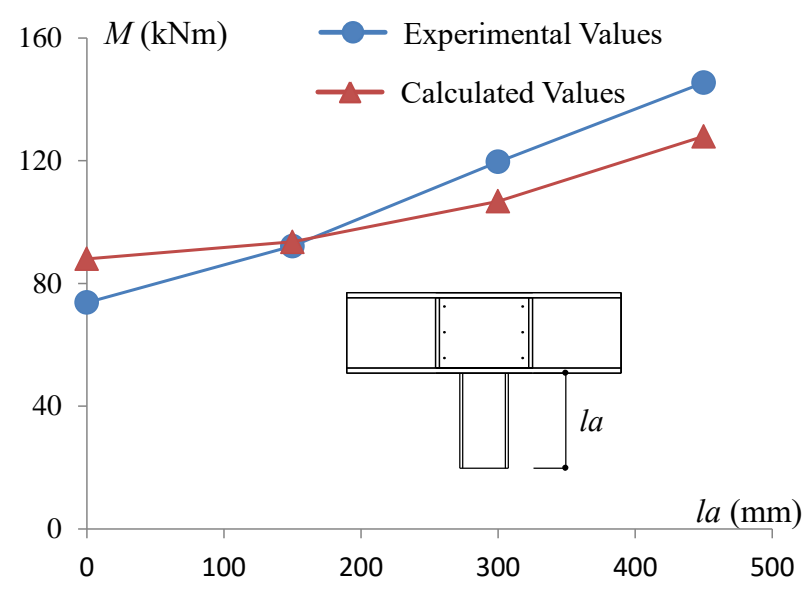

Fig. 9. Comparison of Calculated Values and Experimental Values (Experiment (I))

\subsection{Appropriateness of strength evaluation method (Experiment (I))}

The comparison of the calculated values obtained by the proposed formulae with the test results is shown in Fig. 9 and Table 2. The vertical axis represents the moment applied to the joint. The horizontal axis gives the embedded length of the $\mathrm{S}$ column. The calculated values also increase with the embedded length of the $S$ column, similarly to the experimental values. The average value of the ratios $M_{\text {exp. }} / M_{\text {cal }}$. about the experimental values to the calculated values was 1.02 , and the calculated values were shown to be in good agreement with the test results. However, the effect of the embedded S column length which influence on the calculated values was slightly smaller than that of the experimental values. A detailed study on a method capable of estimating ultimate bearing strength of the exterior joints while taking account of the effect of the embedded S column length will be carried out.

\subsection{Destructive and Hysteresis property (Experiment (II))}

Concrete crushing in the maximum load and load-displacement relationships are shown in Fig. 10. The vertical axis represents the applied load at the column. The horizontal axis gives the deflection of the column relative to the beam at the end of the column. ${ }_{c} Q_{u}$ shown in Fig. 10 is the bending strength to plastic bending moment of RC column considering the $\mathrm{S}$ column, and $Q_{\max }$ is the maximum load. Regardless of the experimental variables, the punching shear failure of the concrete topping above the steel beem were observed in the maximum load similarly to the crack patterns of Specimen TB$2 \mathrm{D}$ with the embedded $\mathrm{S}$ column length of $300 \mathrm{~mm}$. On the other hand, all specimens had a stable hysteresis property though the punching shear failure at the inner panel were observed. Also deterioration of the strength after the maximum load were similarly to that of Specimen TB-2D.

Fig. 11 shows the envelop curves for hysteresis loops. For purposes of comparison of the effects of the end plate at the tip of the the 


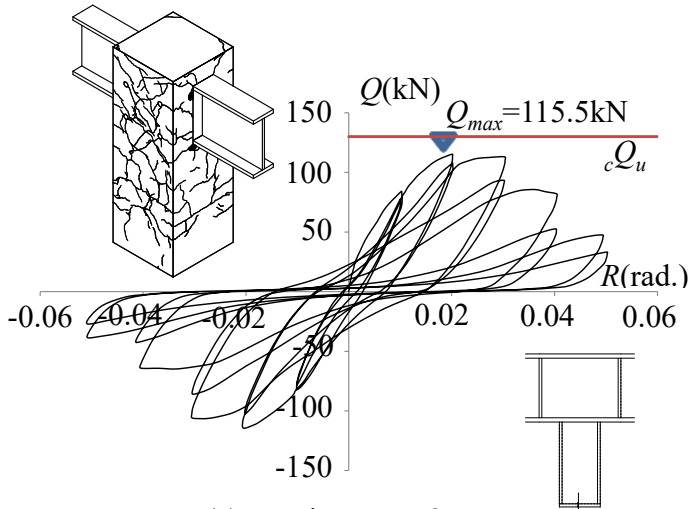

(a) Specimen TB-2DB

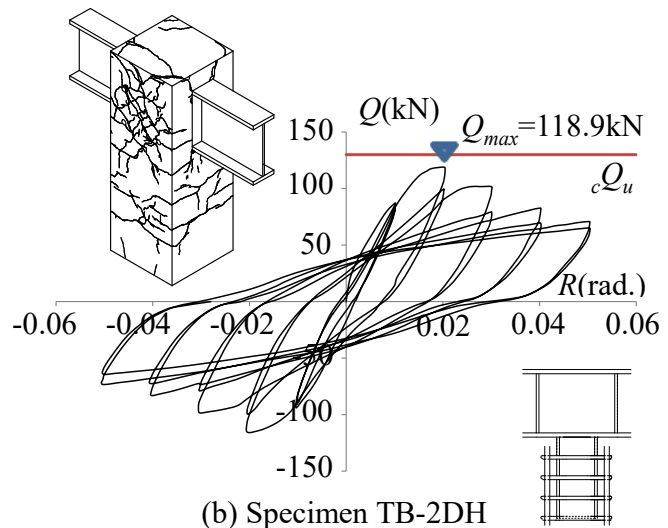

(b) Specimen TB-2DH

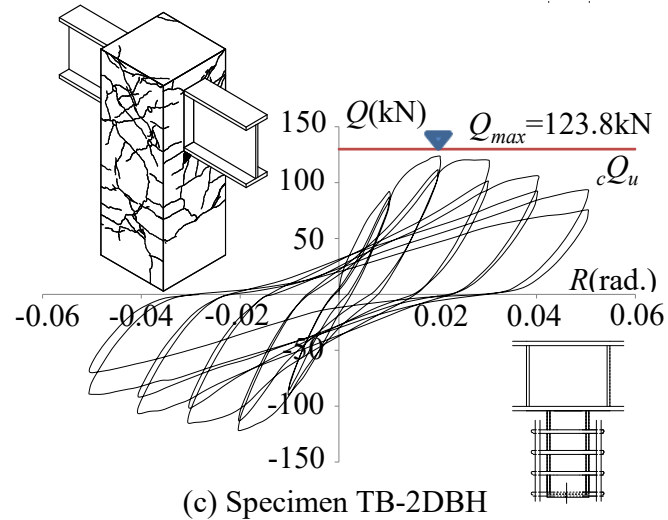

Fig. 10. Stress Trsnsferring Mechanism and Resistance Mechanism of Inner Panel (Experiment (II))

embedded $S$ column and the transverse reinforcement ratio of $\mathrm{RC}$ column arranged around the $\mathrm{S}$ column, the result of Specimen TB$2 \mathrm{D}$ is shown in Fig.11. The maximum load of specimens with the end plate of S column and the transverse reinforcement were larger than that of Specimen TB-2D. Though the effects of these reinforcing elements which influence on the maximum strength were about the same, the bearing failure behavior of the T-shaped joint was more improved by using the transverse reinforcement of $\mathrm{RC}$ column arranged around the $\mathrm{S}$ column. The maximum load of Specimen TB-2DBH with both of these reinforcing

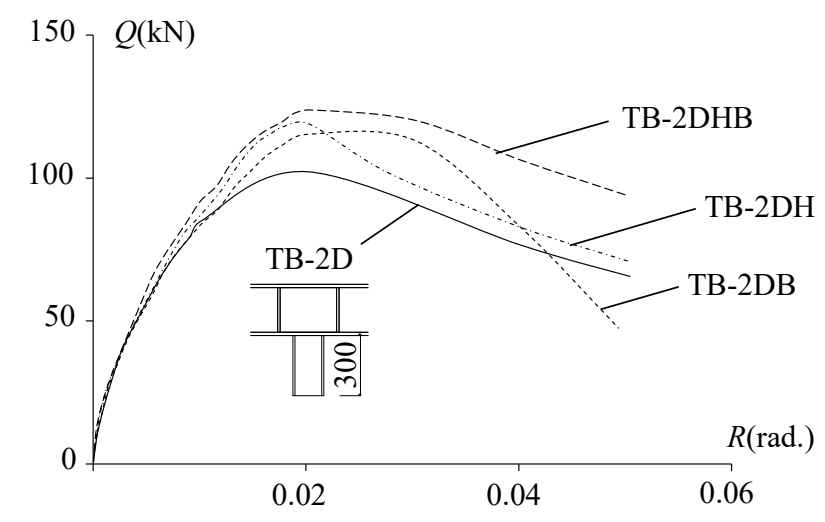

Fig. 11. Envelop Curves for Hysteresis Loops

(Experiment (II))

elements exerted the bending strength of RC column with the S column.

\section{Conclusion}

The following conclusions are drawn from this investigation.

1) In the case of the specimen with a short embedded length of the $S$ column, the punching shear failure of the concrete topping above the steel beem was remarkable when the maximum strength was reached. However, in the specimen with long embedded length of S column, the punching shear failure was not significant observed.

2) The maximum strength increased with the embedded length of the S column. Further, the maximum strength of the specimen with the embedded length of three times of the S column depths is subjected to bending yield strength of the $S$ column.

3) It was shown that the transverse reinforcement to surrounding the $S$ column and the end plate were key components for improving the bearing resistance of the joint.

4) The calculated values were shown to be in good agreement with the test results.

\section{References}

[1] Nishimura Y,Nagamine S. Improvement of Bearing Performance on Exterior S Beam -RC Column Joint. Journal of Structural Engineering 2014; 60(B): 89-95.

[2] Aoyama N, Minamisaka N, Nishimura Y. Ultimate Strength of Joint Connected RC Member with S Member in Series. Proceedings of the Japan Concrete Institute 2007; 29(3): 1315-1320. 